\title{
Efektivitas Latihan Pliometrik dalam Meningkatkan Power Otot Lengan dan Otot Tungkai Atlet Bolavoli: Literature Review
}

\author{
Ridlo Dwi Priyoko, Oni Bagus Januarto* \\ Universitas Negeri Malang, Jl. Semarang No. 5 Malang, Jawa Timur, Indonesia \\ *Penulis korespondensi, Surel: oni.bagus.fik@um.ac.id
}

Paper received: 5-1-2022; revised: 22-1-2022; accepted: 29-1-2022

\begin{abstract}
Review literature study to determine the effect of plyometric training on arm and leg muscle power in volleyball athletes based on secondary data or previous research journal articles related to the variables studied. The literature review data collection used the Preferred Reporting Items for Systematic Reviews and Meta-Analysis (PRISMA) flow method. The search refers to data inclusion criteria (1) research variables according to writing needs (2) experimental research collection methods (3) Sinta and Scopus indexed journals (4) credible data analysis. The results of the analysis show that plyometric training variables have an effective effect on increasing arm and leg muscle power in volleyball athletes. There are several plyometric training methods that can be used and will produce a significant impact if the trainer pays attention to the characteristics of each individual and is supported by the appropriate facilities and equipment.
\end{abstract}

Keywords: plyometric exercise, arm muscle power, leg muscle power

\begin{abstract}
Abstrak
Studi literatur review bertujuan untuk mengetahui efektivitas latihan pliometrik terhadap peningkatan power otot lengan dan otot tungkai atlet bolavoli berdasarkan dari data sekunder atau artikel jurnal penelitian sebelumnya yang terkait dengan variabel diteliti. Pengumpulan data literatur review menggunakan metode alir Preferred Reporting Items for Systematic Reviews and Meta-Analysis (PRISMA). Pencarian mengacu pada kriteria inklusi data (1) variabel penelitian sesuai kebutuhan tulisan (2) metode pengumpulan penelitian eksperimen (3) jurnal terindeks Sinta dan Scopus (4) analisis data secara kredibel. Berdasarkan hasil artikel yang analisis menunjukkan bahwa variabel latihan pliometrik berdampak secara efektif guna meningkatan power otot lengan dan otot tungkai pada atlet bolavoli. Terdapat beberapa metode latihan pliometrik yang dapat digunakan dan akan menghasilkan dampak efektif apabila pelatih memperhatikan karakteristik setiap individu serta didukung dengan fasilitas dan peralatan yang sesuai.
\end{abstract}

Kata kunci: latihan plyometric, power otot lengan, power otot tungkai

\section{Pendahuluan}

Olahraga yakni bentuk aktivitas fisik dengan tujuan mengembangkan kebugaran jasmani maupun rohani apabila dilakukan secara terstruktur dan terprogam yang menyertakan gerakan tubuh dengan berulang-ulang agar memperoleh hasil yang optimal. Selain sebagai aktivitas fisik untuk meningkatkan kebugaran jasmani setiap olahragawan tidak memiliki tujuan yang sama karena olahraga juga sebagai kegiatan rekreasi maupun ajang prestasi. Olahraga prestasi adalah olahraga yang membina dan mengembangkan olahragawan secara terencana, berjenjang, dan berkelanjutan melalui kompetisi untuk mencapai prestasi dengan dukungan ilmu pengetahuan dan teknologi keolahragaan (UU No 3, 2005). Dalam usaha mencetak hasil yang maksimal maka seorang pemain harus memperhatikan berbagai faktor termasuk kondisi fisik maupun faktor penunjung prestasi lainnya. 
Berbicara kondisi fisik Budiwanto (2012:3) menyebutkan bahwa keadaan fisik yang prima adalah alasan yang wajib diperhatikan oleh pemain untuk memperoleh keterampilan teknik dan taktik dengan diindikatori oleh kebugaran jasmani sebagai landasan untuk proses latihan. Sementara Hanafi dkk., (2020:2) mengungkapkan kondisi fisik merupakan komponen yang diperlukan untuk memperoleh keterampilan teknik yang baik, dengan teknik yang baik menunjang pengembangan taktik yang bermanfaat untuk mempersiapkan kemampuan bertanding dan sebagai fondasi dari puncak prestasi. Dari pemaparan tersebut ditarik simpulan jika kondisi fisik adalah alasan yang mendasar dalam program latihan karena teknik maupun taktik dapat dikembangkan apabila atlet mempunyai keadaan fisik yang prima sebagai persiapan bertanding.

Peningkatan keadaan fisik sangat diperlukan dengan tujuan agar keahlian fisik seorang atlet meningkat ke kondisi prima dan bermanfaat guna melakukan kegiatan olahraga dalam menghasilkan prestasi yang optimal. Suatu hal faktor penunjang fisik yang perlu diperhatikan adalah kondisi fisik berupa power. Daya ledak atau power menurut Narlan \& Juniar (2020:87) terdapat dua faktor keadaan fisik yang harus menunjang, yakni kekuatan maksimal dan kecepatan, karena saat seorang atlet yang memiliki kemampuan melakukan gerakan yang kuat dan cepat maka akan menghasilkan power (daya ledak) yang baik. Faktor tersebut perlu dilakukan dengan level yang mengharuskan seorang atlet siap bertanding. Peningkatan kondisi fisik berupa power agar sesuai pada kebutuhan, maka perlu dilakukan secara rutin pada beban yang tepat melalui program latihan.

Daya ledak otot lengan dan otot tungkai merupakan komponen fisik yang harus dimiliki oleh atlet. Diperlukan latihan kondisi fisik yang benar, teratur, dan bertahap serta pemecahan masalah prestasi untuk mencapai hasil daya ledak otot lengan dan otot tungkai yang maksimal. Sesuai dengan penelitian oleh Heldayana dkk., (2016) memaparkan jika power otot lengan berperan pada kekuatan dan kecepatan saat melakukan smash, serta kemampuan untuk memukul bola sekeras mungkin. Hal ini diharapkan bagi setiap atlet melakukan prosedur latihan guna melakukan peningkatan power otot lengannya. Dengan daya ledak atau power otot lengan yang besar, memungkinkan hasil pukulan service maupun saat melakukan smash akan lebih keras dan cepat, sehingga akan menghasilkan tingkat keberhasilan yang besar pula. Sedangkan power otot tungkai mempunyai beberapa unsur untuk meningkatkan kinerja atlet dengan cara yang tepat dengan melibatkan otot dan jaringan ikat dalam gerakan eksplosif dihampir semua cabang olahraga (Hansen \& Kennelly, 2017:1). Artinya semakin besar kekuatan otot tungkai untuk melakukan tumpuan atau lompatan, maka akan semakin stabil saat melayang dan hasil lompatan akan semakin tinggi.

Permainan bolavoli adalah kegiatan olahraga yang dilakukan secara beregu dan setiap regu terdapat enam pemain. Teknik dasar dalam permainan bolavoli membutuhkan kondisi fisik yang baik sebagai persiapan atlet untuk bertanding. Menurut Mustafa (2015:10) teknik merupakan cara praktik gerakan tertentu yang dilakukan pemain secara efektif dan efisien pada saat bermain bolavoli terdiri atas service, passing bawah, passing atas, smash, dan block. Unsur fisik berupa daya ledak otot lengan dan otot tungkai berguna untuk mendukung teknik dasar dalam permainan bolavoli. Seperti halnya diungkap oleh Kardiyanto \& Sunardi (2020:8) guna mencetak atlet bolavoli secara optimal dibutuhkan dorongan keahlian fisik secara optimal pula. Contohnya saat melakukan smash sebagai perlawanan dasar guna melumpuhkan permainan dan memperoleh poin diperlukan lompatan yang tinggi dan pukulan keras serta terarah. Saat melakukan teknik block yang baik, atlet harus memiliki daya jangkauan yang 
tinggi sebagai pertahanan dari serangan lawan. Dengan demikian, diperlukan kekuatan dan kecepatan atau kekuatan otot lengan dan otot tungkai dalam meningkatkan teknik dasar permainan bolavoli.

Permasalahan dalam pencapaian prestasi yang masih minimal dan faktor penunjang yang belum maksimal menjadikan dasar dan alasan pelatih guna mempersiapkan metode latihan yang sesuai oleh atlet. Melalui program latihan yang disusun dengan baik akan mampu mengembangkan potensi yang dimiliki oleh atlet dari aspek fisik maupun teknik dasar dalam permainan bolavoli. Hanafi dkk., (2020:5) menyebutkan bahwasanya peranan pelatih sangatlah penting dalam memberikan program latihan yang beragam dengan disesuaikan karakter perkembangan atlet yang dibina. Program latihan harus disusun sesuai dengan kebutuhan sehingga tercapainya prinsip spesifikasi dalam cabang olahraga. Namun perlu diketahui bahwasanya tidak semua program latihan yang diberikan oleh pelatih dapat diterima dengan mudah, karena bagi atlet dibutuhkan adaptasi dalam penerapannya. Apabila aspek tersebut dapat diperhatikan, maka diharapkan atlet akan lebih siap untuk mencapai top performance.

Sebagai salah satu bentuk latihan fisik, metode latihan pliometrik merupakan program latihan yang bisa diterapkan pelatih guna mengatasi masalah dalam melakukan peningkatan power otot lengan dan otot tungkai pada atlet bolavoli. Krisdasuwarso \& Hakim (2020:31) mengatakan membangun kekuatan otot pada satu kali kontraksi dan begitu cepat sesuai tahanan (beban) bagi seorang atlet diperlukan latihan beban dan kecepatan, serta latihan pliometrik. Latihan pliometrik yakni suatu hal program latihan utama dan bisa membuat peningkatan kekuatan dan kecepatan yang dinamakan dengan daya ledak. Model program latihan tersebut bisa memperoleh tahanan guna mendapatkan kemampuan yang optimal dengan periode sesingkat- singkatnya. Neuro muscular merupakan energi yang digunakan dalam program latihan pliometrik ini, dengan menggunakan kekuatan pada satuan yang tinggi dalam periode yang singkat (Harmandeep dkk., 2015:1).

Tidak dapat dipungkiri bahwa keadaan fisik yakni suatu hal unsur mendasar dan diperlukan untuk atlet. Dengan keadaan fisik yang prima juga pada faktor penunjang lainnya dapat menghasilkan prestasi yang optimal. Teknik maupun taktik dapat dikembangkan apabila atlet memilki kondisi fisik yang baik dengan melakukan program latihan yang sesuai. Namun terkadang terdapat beberapa masalah seperti yang telah dipaparkan dari pendapat sebelumnya. Melalui program latihan yang disusun dengan baik akan mampu mengembangkan potensi atlet. Dengan program latihan pliometrik diharapkan dapat meningkatkan kondisi fisik daya ledak otot lengan dan otot tungkai lalu bisa mengembangkan cara dalam permainan bolavoli.

Terdapat beberapa penelitian bahwa latihan pliometrik dapat menunjukkan adanya pengaruh yang positif terhadap power otot lengan dan otot tungkai atlet bolavoli. Penelitian oleh Arifin dkk., (2017) diperoleh hasil bahwa latihan squat jump dan standing jump berdampak positif pada power otot tungkai atlet bolavoli. kemudian penelitian dari Arizal \& Lesmana, (2019) menunjukkan hasil bahwa latihan pliometrik berdampak efisien pada kemampuan smash bolavoli. Lalu penelitian dari Foqhaa dkk., (2021) diperoleh hasil bahwa program latihan pliometrik spesifik latihan delapan minggu berdampak positif pada peningkatan power otot tungkai, vertical jump, dan performa spike pada pemain bolavoli wanita. sementara penelitian dari Thattarauthodiyil dkk., (2019) menunjukkan bahwa 
program dynamic stretching dengan latihan pliometrik menjadi program latihan yang berdampak positif bagi kinerja vertical jump height pada atlet bolavoli putri. Penelitian terakhir oleh Kim \& Park, (2016) diperoleh hasil bahwa latihan vibration pada seluruh tubuh dengan latihan pliometrik memiliki efek yang berbeda pada peningkatan power otot isokinetik, kinerja melompat, dan keseimbangan atlet bolavoli wanita.

\section{Metode}

Rancangan studi ini menggunakan metode literatur review. Studi ini menggunakan sumber informasi yang diperoleh dari data sekunder yang didapatkan dari beberapa artikel hasil penelitian yang sudah diterbitkan. Metode pengumpulan data article review ini menggunakan akses google scholoar untuk artikel nasional dan artikel internasional. Akses Eric journal untuk artikel jurnal penelitian internasional. Pengumpulan data literatur review menggunakan metode alir Preferred Reporting Items for Systematic Reviews and Meta-Analysis (PRISMA). Pencarian mengacu pada kriteria inklusi data (1) variabel penelitian sesuai kebutuhan tulisan (2) metode pengumpulan penelitian eksperimen (3) jurnal terindeks Sinta dan Scopus (4) analisis data secara kredibel. Penelitian yang dipilih berupa eksperimen, Search term yang digunakan ("latihan pliometrik" terhadap "power otot lengan", "power otot tungkai" "atlet bolavoli", plyometric exercises "explosive power" "arm muscles", "leg muscles" "volleyball athletes"). Berikut ini diagram dengan menggunakan strategi ekstraksi data dan identifikasi yang sesuai dengan diagram aliran prisma (Swartz, 2011).

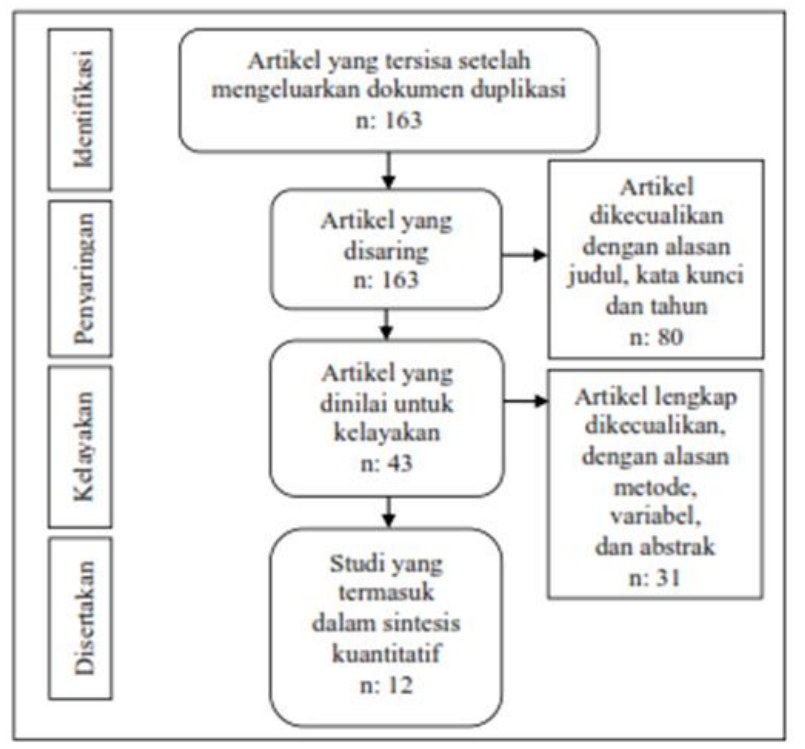

Gambar 1. Alur analisis artikel junal penelitian Nasional 


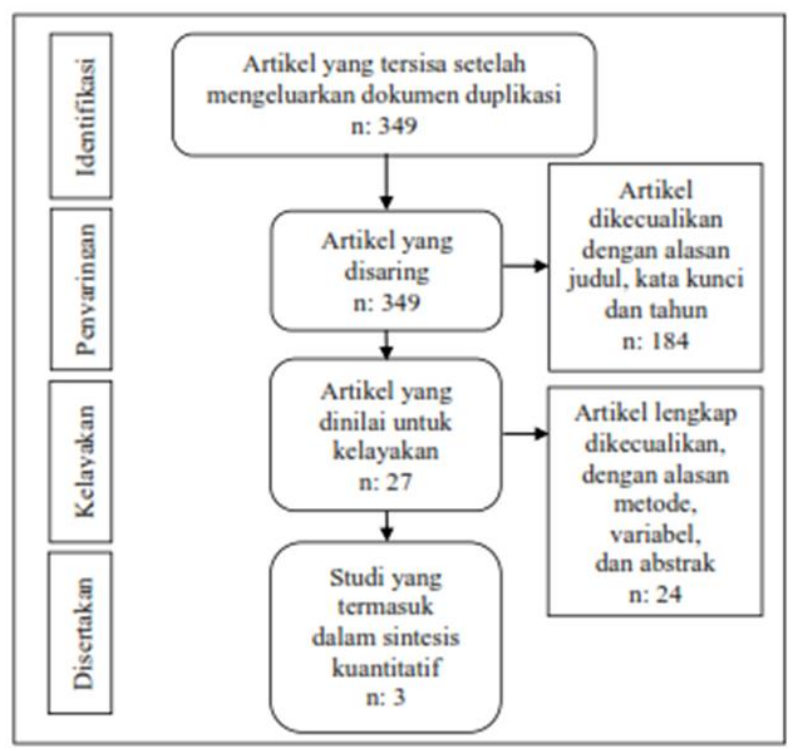

Gambar 2. Alur analisis artikel junal penelitian Internasional

\section{Hasil dan Pembahasan}

\subsection{Hasil}

Berdasarkan hasil pengumpulan artikel jurnal dan menyeleksi kelayakannya sesuai dengan variabel yang akan diteliti dengan kriteria inklusi data untuk membatasi artikel dengan desain tertentu, maka selanjutnya tahap analisis artikel. Berikut ini paparan dari 15 artikel yang telah dianalisis oleh penulis.

Tabel 1. Hasil Analisis Article Review

\begin{tabular}{|c|c|c|c|c|c|c|}
\hline No. & Nama & Tahun & $\begin{array}{l}\text { Rencana } \\
\text { Penelitian }\end{array}$ & $\begin{array}{l}\text { Metode } \\
\text { Pengumpulan } \\
\text { Data }\end{array}$ & Responden & $\begin{array}{l}\text { Desain } \\
\text { Penelitian }\end{array}$ \\
\hline 1 & $\begin{array}{l}\text { Bagaskara } \\
\& \\
\text { Suharjana }\end{array}$ & 2019 & $\begin{array}{l}\text { Two } \\
\text { groups } \\
\text { pretest- } \\
\text { posttest } \\
\text { design }\end{array}$ & $\begin{array}{l}\text { Tes keahlian } \\
\text { vertical jump }\end{array}$ & $\begin{array}{l}47 \text { atlet } \\
\text { klub } \\
\text { bolavoli } \\
\text { Ganevo Usia } \\
14-17 \\
\text { Tahun }\end{array}$ & Eksperimen \\
\hline 2 & Indrayana & 2018 & $\begin{array}{l}\text { Pretest- } \\
\text { postest }\end{array}$ & $\begin{array}{l}\text { Tes daya ledak } \\
\text { otot tungkai } \\
\text { dan tes } \\
\text { keahlian smash }\end{array}$ & $\begin{array}{l}12 \text { atlet } \\
\text { bolavoli } \\
\text { SMK N } 1 \\
\text { Kota Jambi }\end{array}$ & Eksperimen \\
\hline 3 & $\begin{array}{l}\text { Pratiwi, } \\
\text { dkk }\end{array}$ & 2018 & $\begin{array}{l}\text { Pretest- } \\
\text { postest }\end{array}$ & $\begin{array}{l}\text { Tes kekuatan } \\
\text { otot tungkai } \\
\text { dan tes daya } \\
\text { ledak otot } \\
\text { tungkai }\end{array}$ & $\begin{array}{l}30 \text { atlet } \\
\text { SMAN } 1 \\
\text { Tarik }\end{array}$ & Eksperimen \\
\hline 4 & $\begin{array}{l}\text { Cahyono, } \\
\text { dkk }\end{array}$ & 2018 & $\begin{array}{l}\text { Matching- } \\
\text { only design }\end{array}$ & $\begin{array}{l}\text { Tes keahlian } \\
\text { push up } 30 \\
\text { detik, tes push } \\
\text { up } 60 \text { detik, }\end{array}$ & $\begin{array}{l}40 \text { atlet } \\
\text { SMAN } 2 \\
\text { Kabupaten } \\
\text { Lamongan }\end{array}$ & Eksperimen \\
\hline
\end{tabular}




\begin{tabular}{|c|c|c|c|c|c|c|}
\hline No. & Nama & Tahun & $\begin{array}{l}\text { Rencana } \\
\text { Penelitian }\end{array}$ & $\begin{array}{l}\text { Metode } \\
\text { Pengumpulan } \\
\text { Data }\end{array}$ & Responden & $\begin{array}{l}\text { Desain } \\
\text { Penelitian }\end{array}$ \\
\hline 5 & $\begin{array}{l}\text { Pembayun, } \\
\text { dkk }\end{array}$ & 2018 & $\begin{array}{l}\text { Matching- } \\
\text { only design }\end{array}$ & $\begin{array}{l}\text { dan tes } \\
\text { medicine ball } \\
\text { tes kekuatan } \\
\text { otot tungkai } \\
\text { dan daya ledak } \\
\text { tungkai dengan } \\
\text { leg dynamo } \\
\text { meter dan } \\
\text { jump MD }\end{array}$ & $\begin{array}{l}44 \text { atlet } \\
\text { SMA Negeri } \\
1 \text { Ngunut }\end{array}$ & Eksperimen \\
\hline 6 & $\begin{array}{l}\text { Purbasari, } \\
\text { dkk }\end{array}$ & 2016 & $\begin{array}{l}\text { Matching } \\
\text { pre-test } \\
\text { post-test } \\
\text { control } \\
\text { grup } \\
\text { design }\end{array}$ & $\begin{array}{l}\text { Tes keahlian } \\
\text { daya ledak otot } \\
\text { lengan }\end{array}$ & $\begin{array}{l}20 \text { atlet } \\
\text { klub } \\
\text { bolavoli } \\
\text { Gajayana } \\
\text { Kota Malang }\end{array}$ & Eksperimen \\
\hline 7 & $\begin{array}{l}\text { Oktaviani } \\
\text { \& Donie }\end{array}$ & 2020 & $\begin{array}{l}\text { Pretest- } \\
\text { postest }\end{array}$ & $\begin{array}{l}\text { Tes daya ledak } \\
\text { otot tungkai } \\
\text { dan tes } \\
\text { keahlian smash }\end{array}$ & $\begin{array}{l}35 \text { atlet } \\
\text { terdiri } 15 \\
\text { putra dan } \\
20 \text { putri } \\
\text { SMAN } 01 \\
\text { Mukomuko }\end{array}$ & Eksperimen \\
\hline 8 & Hardovi & 2019 & $\begin{array}{l}\text { Pretest- } \\
\text { postest }\end{array}$ & $\begin{array}{l}\text { Tes lompat } \\
\text { tegak, alat ukur } \\
\text { jump meter } \\
\text { digital }\end{array}$ & $\begin{array}{l}12 \text { atlet Smp } \\
\text { Negeri } 5 \\
\text { Jember }\end{array}$ & Eksperimen \\
\hline 9 & Lestari & 2019 & $\begin{array}{l}\text { One group } \\
\text { pree test- } \\
\text { post test }\end{array}$ & $\begin{array}{l}\text { Tes vertical } \\
\text { jump block }\end{array}$ & $\begin{array}{l}45 \text { atlet } \\
\text { Smkn } 1 \\
\text { Kota } \\
\text { Bengkulu }\end{array}$ & Eksperimen \\
\hline 10 & $\begin{array}{l}\text { Hermawan } \\
\text { \& Hartanto }\end{array}$ & 2018 & $\begin{array}{l}\text { treatment } \\
\text { by level } \\
2 \times 2\end{array}$ & $\begin{array}{l}\text { Tes keahlian } \\
\text { jump service }\end{array}$ & $\begin{array}{l}\text { Atlet club } \\
\text { Tunas } \\
\text { Rafflesia } \\
\text { Kota } \\
\text { Bengkulu }\end{array}$ & Eksperimen \\
\hline 11 & $\begin{array}{l}\text { Hidayat, } \\
\text { dkk }\end{array}$ & 2020 & $\begin{array}{l}\text { control } \\
\text { groups } \\
\text { pretest- } \\
\text { posttest } \\
\text { design }\end{array}$ & $\begin{array}{l}\text { Tes vertical } \\
\text { jump (otot } \\
\text { tungkai) dan } \\
\text { tes medicine } \\
\text { ball throw test } \\
\text { (otot lengan) }\end{array}$ & $\begin{array}{l}23 \text { atlet } \\
\text { yaitu } 12 \\
\text { orang putra } \\
\text { dan } 11 \\
\text { orang putri }\end{array}$ & Eksperimen \\
\hline 12 & Daryono & 2018 & $\begin{array}{l}\text { One-Group } \\
\text { Pratest- } \\
\text { Posttest }\end{array}$ & Tes service & $\begin{array}{l}15 \text { atlet } \\
\text { SMK YP } \\
\text { Gajah Mada } \\
\text { Palembang }\end{array}$ & Eksperimen \\
\hline 13 & $\begin{array}{l}\text { Makaruk, } \\
\text { dkk }\end{array}$ & 2014 & $\begin{array}{l}\text { Pretest- } \\
\text { postest }\end{array}$ & $\begin{array}{l}\text { Tes vertical } \\
\text { jump }\end{array}$ & 33 atlet & Eksperimen \\
\hline 14 & $\begin{array}{l}\text { Çımenl, } \\
\text { dkk }\end{array}$ & 2016 & $\begin{array}{l}\text { Pretest- } \\
\text { postest }\end{array}$ & $\begin{array}{l}\text { Tes vertical } \\
\text { jump }\end{array}$ & 36 atlet & Eksperimen \\
\hline 15 & İnce & 2019 & $\begin{array}{l}\text { Pretest- } \\
\text { postest }\end{array}$ & $\begin{array}{l}\text { Tes power } \\
\text { tungkai dan tes } \\
\text { vertical jump }\end{array}$ & 34 atlet & Eksperimen \\
\hline
\end{tabular}


Artikel jurnal penelitian yang dianalisis adalah rentang tahun 2010 hingga 2020 dengan berdasarkan nama penulis, tahun terbit, rencana penelitian, metode pengumpulan data, responden, dan desain penelitian. Dari paparan data pada tabel yang dianalisis artikel jurnal penelitian secara keseluruhan menggunakan rancangan penelitian eksperimen dengan rencana penelitian pretest-postest. Selanjutnya artikel jurnal penelitian rata-rata menggunakan metode pengumpulan data seperti tes vertical jump, dan tes keterampilan teknik dasar permainan bolavoli.

Responden pada artikel jurnal penelitian ini bervariasi dengan berjumlah rentang antara 12-47 responden. Namun dari keseluruhan responden yang seragam adalah atlet bolavoli. Sampel pada penelitian ini rata-rata melalui teknik purposive sampling. Hasil dari pencarian artikel jurnal terkait menunjukkan bahwa variabel yang diteliti saling berhubungan. Selanjutnya penulis memilah jurnal dengan memfokuskan metode penelitian yang digunakan untuk mengetahui kesamaan variabel yang diteliti dan tahun terbitan jurnal sehingga jurnal yang dianalisis bersifat up to date.

\subsection{Pembahasan}

Penelitian mengenai latihan pliometrik berdampak secara efektif guna meningkatkan power otot lengan dan otot tungkai menarik untuk diteliti sebagai upaya merancang program latihan yang sesuai bagi atlet bolavoli. berikut ini akan dibahas dengan analisa review guna mengetahui dampak yang digunakan dari variabel yang diteliti dan membandingkan metode latihan mana yang lebih efektif dari metode latihan lainnya.

\subsubsection{Latihan Pliometrik dengan Power Otot Lengan}

Sebagai upaya untuk meningkatkan power otot lengan pada atlet bolavoli guna menghasilkan prestasi yang optimal maka dibutuhkan program latihan yang sesuai yaitu dengan metode latihan pliometrik. Program latihan tersebut bisa menghasilkan tahanan guna mendapatkan kemampuan yang optimal dengan periode secara singkat sehingga menghasilkan gerakan yang lebih dinamis atau eksplosif. Untuk menghasilkan peningkatan pada kemampuan otot lengan pada atlet bolavoli program latihan pliometrik yang dapat digunakan yaitu pliometrik medicine ball throw, latihan pull up dan latihan push up, medicine ball put dan plyometric push up.

Berdasarkan hasil penelitian oleh Hidayat dkk., (2020) menyatakan bahwa peningkatan kemampuan otot lengan secara signifikan disebabkan karena melakukan pelatihan dengan penerapan teknik complex training. Metode ini bisa dimanfaatkan bagi badan di area atas ataupun di area bawah. Faktor yang terdapat pada metode complex training mempunyai peran penting saat melakukan pengembangan kemampuan atlet bolavoli. Sedangkan unsur latihan beban untuk meningkatkan power otot lengan yang digunakan berupa barbell, beban tubuh dan medicine ball throw.

Selanjutnya penelitian lain oleh Daryono, (2018) menunjukkan bahwa kelemahan dari service atas bagi seorang atlet disebabkan karena tidak mempunyai power otot lengan yang kuat sehingga pukulan yang dihasilkan tidak sampai melewati net atau bola yang dihasilkan dapat dengan mudah diambil oleh lawan. Guna melakukan peningkatan kemampuan otot lengan bisa diterapkan melalui cara latihan beban melalui penggunaan latihan pull up dan latihan push up. Latihan ini sangat efektif apabila dilakukan secara teratur dan kontinyu yang 
berfungsi untuk meningkatkan kinerja otot lengan, bertambahnya power yang dihasilkan sehingga kemampuan dalam melakukan service atas dapat menambah tingkat keberhasilannya.

Menurut Purbasari dkk., (2016) dalam hasil penelitiannya bahwa metode latihan pliometrik melalui bantuan orang lain dan latihan pliometrik dengan diri sendiri dengan menggunakan tes medicine ball put berdampak positif terhadap peningkatan power otot lengan atlet bolavoli. Terakhir penelitian yang dilakukan oleh Cahyono dkk., (2018) pada latihan traditional push up dampak efektif yang mengalami kenaikan yakni komponen fisik yang berupa kemampuan dan daya tahan. Lalu latihan plyometric push up berdampak pada kemampuan fisik kekuatan dan power. Sementara untuk latihan incline push up berpengaruh terhadap kemampuan kekuatan dan daya tahan otot lengan. Sehingga plyometric push up merupakan program latihan terhadap peningkatan kinerja power otot lengan bagi atlet bolavoli. Dari berbagai metode latihan pliometrik yang digunakan di atas untuk meningkatkan power otot lengan bagi atlet bolavoli tentunya harus diimbangi dengan program latihan yang telah disusun dan terencana dengan memperhatikan karakteristik setiap individu sehingga program latihan yang dilakukan lebih efektif dan efesien untuk mencapai puncak prestasi.

\subsubsection{Latihan Pliometrik dengan Power Otot Tungkai}

Dalam hasil penelitian yang telah dianalisis bahwa guna melakukan peningkatan kemampuan daya ledak otot tungkai sehingga menghasilkan lompatan secara maksimal maka diperlukan metode latihan yang tepat yaitu dengan menggunakan latihan pliometrik. Adanya macam-macam metode latihan pliometrik dan bisa dilakukan yakni jump to box, standing jump, knee tuck jump, double leg bound, plyometric front cone hops, counter movement jump, depth jump, single leg depth jump, plyometric squat jump, jump rope, jump service barrier hops, splitstyle hang snatch dan clean \& jerk.

Terdapat adanya metode latihan pliometrik dan bila dibandingkan kelihatan lebih efisien daripada metode latihan pliometrik lainnya untuk meningkatkan power otot tungkai pada atlet bolavoli. Bagaskara \& Suharjana, (2019) dalam hasil penelitiannya menyatakan bahwa dengan metode latihan plyometric box jump dan plyometric standing jump pada keahlian vertical jump terhadap atlet bolavoli mengalami peningkatan. Dalam metode ini latihan plyometric standing jump berdampak efektif guna peningkatan vertical jump daripada latihan plyometric box jump. Kemudian penelitian dari (Indrayana, 2018) diperoleh hasil bahwa metode latihan pliometrik knee tuck jump dan double leg bound berpengaruh terhadap kemampuan otot tungkai dalam permainan bolavoli. Latihan knee tuck jump tidak lebih berdampak efesien pengaruhnya daripada latihan double leg bound terhadap daya ledak otot tungkai. Akan tetapi metode latihan pliometrik knee tuck jump dan double leg bound tidak terdapat pengaruh signifikan pada keahlian smash dalam permainan bolavoli.

Selanjutnya penelitian dari Pratiwi dkk., (2018) menunjukkan bahwa metode latihan front cone hops dan counter movement jump dengan metode latihan pliometrik yang cenderung lebih berpengaruh terhadap power otot tungkai adalah latihan pliometrik front cone hops. Lalu penelitian dari Pembayun dkk., (2018) dengan menggunakan tiga metode latihan pliometrik jump to box, depth jump, dan leg depth jump berpengaruh signifikan terhadap peningkatan kekuatan dan power otot tungkai. Agar mendapatkan hasil yang maksimal maka penyusunan 
program latihan harus berdasarkan prinsip individual karena setiap atlet memiliki kemampuan dan karakter yang berbeda-beda.

Menurut Hardovi, (2019) dalam penelitiannya diperoleh hasil bahwa metode latihan pliometrik squat jump dan depth jump berpengaruh pada meningkatnya kemampuan otot tungkai dalam atlet bolavoli. kemudian penelitian dari Lestari, (2019) menunjukkan bahwa metode latihan pliometrik jump rope dan depth jump berdampak positif pada peningkatan lompatan block smash pada atlet bolavoli. Sementara metode latihan pliometrik oleh penelitian yang dilakukan Hermawan \& Hartanto, (2018) diperoleh hasil apabila metode latihan box jump berdampak positif pada keahlian jump service dan daripada metode latihan pliometrik barrier hops.

Terakhir penelitian yang dilakukan oleh İnce, (2019) menunjukkan bahwa latihan pliometrik split-style hang snatch dan clean \& jerk berpengaruh yang signifikan untuk meningkatkan power kaki, spike jump, waktu untuk sprint $5 \mathrm{~m}$ dan $20 \mathrm{~m}$, dan perubahan arah gerakan pada atlet bolavoli wanita. Dari beberapa program latihan pliometrik yang digunakan pada peningkatan kemampuan otot tungkai pada atlet bolavoli diharapkan untuk pelatih menerapkan variasi latihan dan hasilnya akan terlihat maksimal apabila latihan ini didukung dengan fasilitas dan peralatan yang sesuai.

\section{Simpulan}

Sesuai hasil analisa data pada penelitian mengenai literatur review, maka ditarik simpulan latihan pliometrik berdampak positif dalam meningkatnya power otot lengan dan otot tungkai pada atlet bolavoli. Terdapat beberapa metode latihan pliometrik yang dapat digunakan dan terdapat metode latihan apabila dibandingkan terlihat lebih efisien daripada metode latihan pliometrik lainnya. Namun, Metode latihan akan mendapatkan hasil yang maksimal jika pelatih memberikan latihan yang bervariasi dengan didukung fasilitas dan peralatan yang sesuai dan memperhatikan karakteristik setiap individu sehingga program latihan yang dilakukan lebih efektif dan efesien untuk mencapai puncak prestasi.

\section{Daftar Rujukan}

Arifin, W. F., Saichudin, \& Yunus, M. (2017). Perbedaan Pengaruh Latihan Squat Jump dengan Standing Jump terhadap Tinggi Loncatan Pemain Bolavoli Putrs FIP Universitas Negeri Malang. Jurnal Sport Science, $3(2)$.

Arizal, Y., \& Lesmana, H. S. (2019). Pengaruh Latihan Plyometric terhadap Kemampuan Smash Bolavoli. Jurnal Patriot, 1(3), 1124-1138.

Bagaskara, B. A., \& Suharjana. (2019). Plyometric Standing Jump Terhadap Kemampuan Effect of Plyometric Box Jump and Plyometric Standing Jump Toward Vertical Jump Ability in. Medikora, XVIII(2), 64-69.

Budiwanto, S. (2012). Metodologi Latihan OLahraga. Fakultas Ilmu Keolahragaan Universitas Negeri Malang.

Cahyono, F. D., Wiriawan, O., \& Setijono, H. (2018). Pengaruh Latihan Traditional Push Up, Plyometric Push Up, dan Incline Push Up Terhadap Kekuatan Otot Lengan, Power Otot Lengan, dan Daya Tahan Otot Lengan. Jurnal SPORTIF : Jurnal Penelitian Pembelajaran, 4(1), 54.

Çımenlı, O., Koç, H., Çımenlı, F., \& Kaçoğlu, C. (2016). Effect of an eight-week plyometric training on different surfaces on the jumping performance of male volleyball players. Journal of Physical Education and Sport, 16(1), 162-169.

Daryono, D. (2018). Pengaruh Latihan Kekuatan Otot Lengan Terhadap Hasil Pukulan Service Atas Pada Peserta Ekstrakurikuler Bola Voli. Jurnal Penjakora, 5(2), 86-91.

Foqhaa, B., Brini, S., Alhaq, I. A., \& Nairat, Q. (2021). Eight Weeks Plyometric Training Program Effects on Lower Limbs Power and Spike Jump Performances in University Female Volleyball Players. The Swedish Journal of Scientific Research, 8(1), 1-7. 
Hanafi, M., Prastyana, B. R., \& Utomo, G. M. (2020). Metodologi Kepelatihan Olahraga Tahapan \& Penyusunan Program Latihan (p. 35). CV. Jakad Media Publishing.

Hansen, D., \& Kennelly, S. (2017). Plyomrtric Anatomy. Canada: Human Kinetics.

Hardovi, B. H. (2019). Pengaruh Pelatihan Plyometric Squat Jump Dan Depth Jump Terhadap Daya Ledak Pada Pemain Bola Voli Di Smp Negeri 5 Jember. Jp.Jok (Jurnal Pendidikan. Jasmani, Olahraga Dan Kesehatan, $3(1)$.

Harmandeep, S., Satinder, K., Amita, R., \& Anupriya, S. (2015). Effects of Six-Week Plyometrics on Vertical Jumping Ability of Volleyball Players. Research Journal of Physical Education Sciences ISSN, 3(4), 1-4.

Heldayana, H., Supriyatna, A., \& Imanudin, I. (2016). Hubungan Antara Power Otot Lengan dan Otot Tungkai dengan Hasil Spike Semi pada Cabang Olahraga Bola Voli. Jurnal Terapan Ilmu Keolahragaan, 1(1), 45. Hermawan, \& Hartanto, R. (2018). Pengaruh Metode Latihan dan Power Terhadap Kemampuan Jump Service Bola Voli. Gladi Jurnal Ilmu Keolahragaan, 09(02), 108-118.

Hidayat, A., Pratama, R., \& Makorohim, M. F. (2020). Complex Training: Efektifitas Latihan Dalam Meningkatkan Power Otot Pada Atlet Bola Voli Remaja. Journal Sport Area, 5(1), 76-83.

İnce, İ. (2019). Effects of split style olympic weightlifting training on leg stiffness vertical jump change of direction and sprint in collegiate volleyball players. Universal Journal of Educational Research, 7(1), 2431.

Indrayana, B. (2018). Perbedaan Pengaruh Latihan Knee Tuck Jump Dengan Latihan Double Leg Bound Terhadap Peningkatan Power Otot Tungkai Dan Kemampuan Smash Pada Ekstrakurikuler Bola Voli Putra SMKN 1 Kota Jambi. Jorpres (Jurnal Olahraga Prestasi), 14(1), 1-23.

Kardiyanto, D. W., \& Sunardi. (2020). Kepelatihan Bolavoli. Sidoarjo: Zafatama Jawara.

Kim, Y. Y., \& Park, S. E. (2016). Comparison of whole-body vibration exercise and plyometric exercise to improve isokinetic muscular strength, jumping performance and balance of female volleyball players. Journal of Physical Therapy Science, 28(11), 3140-3144.

Krisdasuwarso, B., \& Hakim, A. A. (2020). Biomekanika Olahraga (Bagi Guru dan Pelatih Olahraga) Pemahaman Dasar Tentang Biomekanika Aplikasinya dalam Bidang Olahraga. Surabaya: CV. Jagad Media Publishing.

Lestari, D. S. (2019). Pengaruh Latihan Jump Rope dan Depth Jump Terhadap Lompatan Block Smash Permainan Bola Voli Siswi Ekstrakurikuler SMKN 1 Kota Bengkulu. Kinestetik: Jurnal Ilmiah Pendidikan Jasmani, 3(2)(9), 151-156.

Makaruk, H., Winchester, J., Czaplicki, A., Sacewicz, T., Zieliński, J., \& Sadowski, J. (2014). Effects of assisted and traditional drop jumps on jumping performance. International Journal of Sports Science and Coaching, 9(5), 1217-1225.

Mustafa, P. S. (2015). Panduan Variasi Latihan Service Atas Permainan Bolavoli. Fakultas Ilmu Keolahragaan Universitas Negeri Malang.

Narlan, A., \& Juniar, D. T. (2020). Pengukuran dan Evaluasi Olahraga (Prosedur Pelaksanaan Tes dan Pengukuran dalam Olahraga Pendidikan dan Prestasi). Yogyakarta: CV. Budi Utama.

Oktaviani, S. M. (2020). Pengaruh Latihan Plyometrics Terhadap Kemampuan Daya Ledak Otot Tungkai Dan Kemampuan Smashatlet Bolavoli Sman 01 Mukomuko. Jurnal Patriot, 2(2), 526-536.

Pembayun, D. L., Wiriawan, O., \& Setijono, H. (2018). Pengaruh Latihan Jump To Box, Depth Jump Dan Single Leg Depth Jump Terhadap Peningkatan Kekuatan Otot Tungkai Dan Power Otot Tungkai. Jurnal SPORTIF : Jurnal Penelitian Pembelajaran, 4(1), 87.

Pratiwi, F. Z., Setijono, H., \& Fuad, Y. (2018). Pengaruh Latihan Plyometric Front Cone Hops dan Counter Movement Jump Terhadap Power dan Kekuatan Otot Tungkai. Jurnal SPORTIF : Jurnal Penelitian Pembelajaran, 4(1), 105.

Purbasari, T. I., Hariyoko, \& Wahyudi, U. (2016). Pengaruh latihan pliometrik terhadap power otot lengan atlet putra klub bolavoli gajayana kota malang. Jurnal Pendidikan Jasmani, 26(1), 203-211.

Swartz, M. K. (2011). The PRISMA statement: A guideline for systematic reviews and meta-analyses. Journal of Pediatric Health Care, 25(1), 1-2.

Thattarauthodiyil, U., Shenoy, K. B., \& Mantargi, M. J. S. (2019). Study on the effects of lower body plyometrics and dynamic stretching on vertical jump in female collegiate volleyball players. Saudi Journal of Sports Medicine, 19(2), 51. 
Sport Science and Health, 4(1), 2022, 54-64

UU No 3 Tahun 2005. (2005). Undang-Undang Republik Indonesia Nomor 3 Tahun 2005 Tentang Sistem Keolahragaan Nasional. Presiden RI, 1, 1-53. 